\title{
THE IRREGULARITIES OF TURN-TAKING IN ME BEFORE YOU MOVIE
}

\author{
Purna $^{1}$ Amir Jaya ${ }^{2}$ Rohmana ${ }^{3}$
}

${ }^{1}$ Halu Oleo University, Indonesia.

\section{ARTICLE INFO}

Keywords:

irregularities, turntaking, overlapping, interruption

How to cite:

DOI:

\begin{abstract}
This research is about the analysis irregularities of turntaking on Me Before You movie. The objectives of this research were (1) to describe the types irregularities of turntakings produced by characters in "Me Before You" movie. (2) to describe the reasons of interruption turn-takings happened in the movie. This research used a qualitative method to desribe and analyze the utterance. The technique of data collection were (1) watching the movie entitled $\mathrm{Me}$ Before You (2) identifying the problems in Me Before You movie (3) formulating the research problems (4) determining the objectives of the study (5) determining theories on context and turn-taking to analyze the data (6) collecting the data manually (7) transferring the chosen data into a data sheet (8) reporting the data. The technique of data analysis were (1) The analysis begun with the searching of the types of irregular turn-takings that are interruption and overlap (2) The reasons why interruption and overlaps emerged in the conversation of the movie are then categorized. The result of this research shows that there is $88.88 \%$ of interruption occurred in that movie and $11.11 \%$ is about overlapping occurrence.
\end{abstract}

\section{INTRODUCTION}

The way of people act and make conversation in social interaction with other speakers is discussed in conversation analysis. Conversation analysis, as an approach of spoken discourse analysis, observes behavior of people in their conversational analysis (Paltridge, 2006). In early 1960s, sociologist, Sacks, Schegloff and Jefferson were interested in how social worlds were constructed and recognized by speakers as they take part in conversational discourse (Paltridge, 2006). Conversation analysis is described as a 'naturalistic observational discipline that could deal with the details of social action rigorously, empirically and formally', (Sacks \& Schegloff, in Sert \& Seedhouse, 2011). Sidnell (in Sert \& Seedhouse, 2011) states that the aims of this 
analysis are to describe, analyze, and understand talk as a basic and constitutive feature of human social life.

One of the basic studies in conversation analysis is turn-taking. A turn is the time when a speaker is talking and turn-taking is the skill of knowing when to starts and finish a turn in a conversation (Burns \& Joyce, 1997). People naturally take turn without being nominated. Taking turn can be indicated by doing overlap, gaps, pause, and even do silence. Moreover, turn-taking may depend on some factors such as the topic of conversation, how well the speakers know each other, the relative status of the speakers, and relationship between the speakers (Burns \& Joyce, 1997).

In this study, the researcher uses irregular turn-takings as the objects of investigation. The study of these irregular turn-takings is interesting and important to further observed since this phenomenon cannot be separated away from people's daily life conversation. When people are having conversation, they sometimes do not make a good turn-taking. They do not realize that when interruption or overlap other speakers not be able to get their turn. A speaker who is interruption lot might feel offended and not appreciated. This condition, of course, will affect the interaction between a speaker and listener (Ansori in Jaya, 2003). Hence, it is expected that, study the interlocutors shall know and realize the effect of irregular turn-takings toward the interaction among them and how they should behave in conversation. Beside those all above considerations, there was also another reason why the researcher chose this study. It is all because there were not many researchers who conducted the same study on the same field yet.

It has been known that most of conducted linguistic studies always related to real-world situation. But in this study, the researcher proposed something different. She wanted to investigate the interruption and overlapping in movie because irregular turn-takings which happen in direct conversations in real daily life could also happen in a conversation among actors in a movie. In this case, the actors and actresses, in uttering the dialogues in the movie, do not merely depend on the script has been made by the script researcher; but also try to make some "improvisations" without, of course setting themselver out of the real context of the story. Even though the researcher observed a movie, but she that the movie has real situations because actors and actresses in the movie are demanded to play their characters naturally. The movie observed in this study was the reason behind the researcher decision to choose this movie because she thought that it is able to represent the general characteristics of people's daily life conversations as this movie contained a lot of irregular turntaking that most commonly occur in people daily life.

Based on the above background, the research questions of this study are: (1) What are the irregular turn-takings produced by characters in Me Before You movie?; and (2) What are the reasons of each irregular turn taking produced by characters in Me before You movie?

\section{LITERATURE REVIEW}

\section{Definition of Turn-Taking}

Cutting (2002:29) explains that cooperation in conversation is managed by all participants through turn-taking. Furthermore, explains that in most cultures only one person speaks at a time, then it is continued by another.

Yule (1996:72) explains that there is a scarce commodity called floor which can be defined as the right to speak. Having control of this scarce commodity at any time 
is called a turn. Any situation where control is not fixed in advance, anyone can attempt to get control. This is called turn-taking.

\section{Definition of Turn-Takings Irregularities}

Zimmerman \& West (1975:114) divide the types of turn-taking irregularities in a conversation into "interruption and overlaps". Overlaps are instances of simultaneous speech where next speaker begins to speak at or very close to a possible transition places in a current speaker ${ }^{\text {ee }}$ utterance. Interruption is seen as penetrating the bound areas of a unit-type to the prior to the last lexical constituent that could define a possible terminal boundary of a unit-type. Wardhaugh, (1991: 151) says that interruptions can be referred to as acts that show clarification, repetition, asking for help, rejection, and resolution.

\section{Types of Turn-Taking}

As has been stated in the previous elaborations that in a conversation there are more than one person talking. Turn-taking.in this case when A is talking, B is listening. This act is considered as turn-taking. Turn-taking, in the performance, could be divided into several types; ie., adjacency pairs, interruption, and overlaps. Each type of turn-taking has its own characteristics that make them different between one to another.

a. Organizational change of speech Talk

Sacks, Schegloff, and Jefferson (1974: 969), say that the arrangement of retrieval in a conversation is fundamental. Turn is the most basic unit of conversation, is the change of direction from the flow of speech which is typical of a normal conversation, another with a monologue.

Based on the explanation above, understanding two general rules in determining the next speaker. The first person who is talking can show the next speaker. Or, the second way is the next speaker shows herself to take the explanation.

b. Sequencing organization

One of the principles in speech analysis is that speech utterances in a conversational interaction are sequentially organized (in sequences). The sequence is embedded in a common experience, that is, one start product leads to another. According to Sacks, that's probably why people sometimes refuse to do simple deeds, like greeting, because they really do not want to be involved with what might follow afterwards (Sacks in Have 2007: 130). In relation to the conversation, it means that any utterance contained in an interaction is deemed to have been specially produced for the position in the conversation where the utterance occurs, especially after the utterance of the preceding speech, and at the same time it also creates the context for the subsequent speech (Have 2007: 131).

Concurrent pairing couples or adjacency pairs are the main tools in sequential analysis. The concept of pairing side by side arises because speech appears usually in pairs, misses in greeting, or thanks, or also questions that generally lead to answers from the other person. However, the reality in everyday conversation, the adjoining couple does not always follow. For example, after a question as a first-Pair part then immediately after not always an absolute answer as a second pair of parts. This is explained by Schegloff with the concept of the presence of expansion forms of Adjacency pair. The expansion is divided into pre-expansion, insert-expansion, postexpansion. 


\section{Reasons for Interruption}

Wardhaugh, (1991: 151) says that interruptions can be referred to as acts that show clarification, repetition, asking for help, rejection, and resolution. It can be concluded that one can clarify a speaker's word or phrase, usually he will repeat the sentence or part of the sentence to be clarified.

From the above statement "clarification" that repeating the sentence or the word that asks the question is part of the speech of the previous speaker with a higher intonation or intonation.

Wardhaugh, (1991: 152) says that asking for help is considered a second disorder. As someone asks for help or guidance to someone it will disrupt or hinder their activities. Something like this should state briefly the purpose of interrupting them, asking for help or guidance can also be said to be an interrupt because when two people are talking and suddenly someone else is asking for help to them, the conversation will stop because both or one of them need to help the person. Of course, the act has interrupted the conversation.

Reason to tight address interruption rejection. (Wardhaugh, 1991: 152). Therefore, before a speaker interacts with one of the speakers or swordsmen, the speaker or their incumbent must choose one of them whether they are a state or speaker. With it the listener can do an interruption or clarification of the phantom of the phrase against some points spoken by the speaker. Examples such as, someone sometimes uses the words' patient first! continue! ". It happens also when limiting all the reasons, where the settlement can also be regarded as an interruption.

\section{Overlaps}

"Conversation is cooperative behavior, which means that every person has the sight to speak and he/she cannot monopolize a conversation "(Wardaugh, 1991 :150). However, it seems it is not as simple as that. Sometimes people try to dominate themselves in doing the conversation. They want to dominate topic of the conversation and they want to gain the floor. That action can cause overlap or interruption. As what had been above that besides interruption, the other type of irregular turn-takings, overlap, may also occur when people are eager to gain the floor of the conversation.

The first description comes from Zimmerman \& West (1975) who define overlap as instances of slight over - anticipation by the next speaker: instead of beginning to speak immediately following current speaker's turn, next speakers begins to speak at the very end of current speaker's turn, overlapping the last word (or part of it).

In the conversation above, the second definition taken who explains that overlap is an act of interruption without leaving any pause in a conversation. This will make the second speaker's words heard together at the same time in a conversation.

Overlap may occur in along with the current speaker's utterances or at the end of his sentence. This idea is supported by Coates that overlap happens when a speaker's words are overlapping with the previous speaker's last words or part of it (coates, 1986: 99).

Mills (1995) adds that overlapping segments involves more than the last syllable of a speaker's turn and are usually found when two or more speakers pursue a theme simultaneously.

\section{Research Methodology}


This part covers the discussion about design of the study, data sources, research instrument, data collection, and data analysis.

\section{Design of the study}

The design of this study is descriptive qualitative design. This study described the types of irregular turn-takings that happened in the movie. It also described the type of irregular turn-takings occur, especially in the conversations from all characters in "Me Before You" movie.

\section{Data source}

The data source of this study are the movie and its transcript. The movie was used to see the context and the plot of the movie. If there were some dialogues which cannot be listened perfectly, the researcher used transcript of the movie which was downloaded from

(ttps://www.springfieldspringfield.co.uk/movie_script.php?movie=me). The transcript of the movie then used by the tesearher as secondary source. When she found any interruption happened in the movie, the writer gave mark on the transcript and whenever they are.

\section{Instrument}

The instrument of this study is human instrument which means that the researcher as the main observer of this study. Cresswell as cited in Semitha (2007: 38) stated that "Researcher as a key instrument collects data themselves through examining documents, observing behavior, and interviewing participants.

\section{Subject}

All characters playing in the movie become the subjects of this study. Therefore, the writer collected the data from all characters without considering gender and age.

\section{Procedure of Data Collection}

In conducting the research, some steps were used in the process of the research from the beginning of the research until the final result. The procedure are provided below.

1. Watching the movie entitled Me Before You

2. Identifying the problems in Me Before You movie

3. Formulating the research problems

4. Determining the objectives of the study

5. Determining theories on context and turn-taking to analyze the data

6. Collecting the data manually

7. Transferring the chosen data into a data sheet

8. Reporting the data

\section{Data Analysis Technique}

The following is the procedure of data analysis.

1. The analysis begun with the searching of the types of irregular turn-takings that are interruption and overlap. The searching of interruption and overlap that done based on the definitions, which are already given in the related theories whenever the situation referred to the definition, the writer decided it as an interruption or overlap.

2. The reasons why interruption and overlaps emerged in the conversation of the movie are then categorized. The reasons of interruptions and overlaps are determined based on the context of the movie and based on the theories of 
reasons had been given by some experts. clarification and/or description for each Moreover, the writer provided explanations for the reasons that are unsuitable to the theories above. After analyzing the reasons of interruption and overlaps, the researher finally calculated some numbers of those reasons.

According to Ary et al. (2010), data that has been collected must be organized and managed in order to be described, classified, and interpreted. In order to collect and organize the data, the researcher used symbol. Jefferson in Lerner (2004:24-31) gives the following examples: "//" double oblique indicating an interruption and "=" equal sign indicating no break or gap.

\section{FINDINGS}

\section{Types of Turn-taking Irregularities in Me Before You Movie}

\begin{tabular}{|c|c|}
\hline $\begin{array}{c}\text { Types Turn-taking } \\
\text { Irregularities }\end{array}$ & Total \\
\hline Intteruption & 8 \\
\hline Overlaps & 1 \\
\hline Total & 9 \\
\hline
\end{tabular}

The table show that in "Me Before You" Movie conversation, interruption occurs more than overlap. In which interruption consist of eight charaters while overlaps only one character.

\section{Discussion}

\section{Interruption}

1) Cooperative Interruption

Cooperative interruption was only exist once in this movie. This is because the negative intention of speaker was more often to happen rather than positive intention. There are three types of purposes in Cooperative Interruption, they are to show assistance, clarification, and agreement. However, only assistance purpose existed in the movie and would be discussed below.

\section{1) Assistance}

In many cases of interruption, there are many speakers need to be assisted in uttering something. Most of the cases happened because they are speechless or have no idea to say. From those pauses, the next speaker could see that the speaker had problem in giving his/her utterance and then decided to help by making interruption to the speaker's utterance.

William : So?

Louisa : Well, they could have left!

William : they chose to stay. 


\section{Louisa : Yes, no I get it, being there, gave their lives more meaning, but that's = \\ William : $\quad=$ but you don't agree.}

Louisa : Well, to sacrifice themselves like that! I mean, could you even imagine?

William : but you like the film?

Louisa : I loved it. Oh, if you're laughing at me, I swear to God I will push you out of that chair.

William: I am not laughing at you. the sky is clearing should we get some air?

The conversation above takes place in the watching room of William. This is the first time of Louisa to watch movie with subtitle and new genre. William with cool face was curious to ask Louis' opinion regarding the movie. Louisa was very speechless. When she wanted to express her idea about the film, she gives pause so William thought that this was his time to continue her utterance.

\section{Overlap}

According to Sacks et al. (1974:706), overlap is a type of simultaneous talk that can arise in several ways; they are premature self-selection related to the upcoming TRP, occurring in conjunction with the current TRP, and self-selection at the same time as the current speaker elects to continue. Thus, when the next speaker starts to speak at the very end of the current speaker's turn, an overlap occurs. Moreover, Kurtic et al. (2009:186) argue that overlapping speech is a common phenomenon in naturally occurring conversation. Given that, for the most part conversations proceed smoothly without overlap. The occurrence of an overlap in a conversation and its management by conversational participants require explanation. In addition, there are some types of overlap which further explain more on how overlap occurs in conversation.

After the movie was analyzed, it was found that interruption is not the only one types of irregular turn-takings occurs during the movie conversation, but there is also another type, overlap. Overlap, just like interruption is not the only in the movie because most of the character do not follow the turn-takings rules. They even do not realize the signals for taking the turn that sometimes speak at the very end af current speakers turn-taking, overlapping those current speakers last words or part of it. Additionally, most characters in "Me Before You" movie do the overlap for there are several specific factors or reason they have. The reasons including recognitional.

\section{Conclusions}

Concerning to the first research question, the researcher can conclude that there was $88.88 \%$ of interruption occurred in that movie and $11.11 \%$ of overlapping occurance. Also found in the second research question that disagreement, assistance, tangentialization, showing urgency, and topic change purposes of interruption which exist in the movie. And showing urgency significance also presented in the overlapping irregularities.

The researcher found that there is only one overlapping occurred in this movie because this movie is included in romance genre movie. It means that all the characters have calm personality and minimum conflict. The characters talk in calm way. Also found in interruption, the interruption occurred in the way of hard disagreement form. All the interruption form occurred in polite way. 


\section{REFERENCES}

Ary, et al. (2010) Introduction to Research in Education. Wadsworth: Cengage Learning.

Brown, B., Lerner, R., \& Steinberg., L. (2004). Handbook of Addescent Psychology. New York: Willey.

Burn, Joyce, (1997) Focus on Speaking,(Sydney: Macquarie)..

Cutting, J. 2002. Pragmatics and Discourse. London: Rouledge.

Cook, (1989), Discourse. Oxford: Oxford University Press

Creswell, J. W. (2015). A concise introduction to mixed methods research.

Duncan S.D. (1974). On the structure of speaker-auditor interaction during speaking turns. Lang. Soc. 2 161-180.

Goodwin, C. \& Heritage, J. (1965) 'Conversation analysis', Annual Review of Anthropology 19, 28337.

Goodwin C. (1980). Restarts, pauses, and the achievement of mutual gaze at turn-beginning. Soc. Inq. 50 272-302.

Have, Paul ten. 2007. Doing conversation Analysis. Ed, ke-2. London: Sage Publications ltd.

Jannah, H.L.I. ( 2014 ). Conversational Analysis Of Turn-Taking In "The Social Network" Film. Unpublished Thesis The State Islamic University Maulana Malik Ibrahim of Malang.

Jaya (2003). Turn-Taking Irregularities by African American. English Department, Faculty of etters, Petra Christian University

Kendon A. (1957). Some functions of gaze-direction in social interaction. Acta psychol. 26, 22-63.

Levinson, S. C. 1983. Pragmatics. Cambridge University Press

Li, H. Z. 2001. Cooperative and Intrusive Interruptions in Inter- and Inracultural Dyadic Discourse, Journal of Language and Social Psychology. Vol. 20 No. 3, September 2001 259-284. Sage Publication.

Mills. (1995). Discourse Analysis for language Of language. Cambridge: Cambridge University Press.

Kurtic, E., Brown, G. J. and Wells, B. (2009) Fundamental frequency height as a resource for the management of overlap in Talk-in-interaction. In: Where 
Prosody Meets Pragmatics. Studies in Pragmatics, 8 . Emerald Group Publishing Limited, Bingley, UK ISBN 978-1-84950-631-1.

Paltridge. (2006). A system for conversational Turn-taking. Retrieved July, 15,2009.

Sacks, H, Schegloff, E.A; \& Jefferson, G. (1974). A simplest Systematics for the organization of Turn-taking for Conversation language, 50, 696-735.

Sacks, H., E. A. Schegloff and G. Jefferson. I. N Sert \& S, (1983) A simplest systematics for the organization of turn-taking for conversation. Language, Vol. 50 (4), Part 1 (December 1974) 696-735. Linguistic Society of America.

Traugott, E.C. \& Partt, M.L. (1980). Linguistics for students of literature. New york: Harcourt Brace Jocanvic.

Tiono, I. N \& Ansori. A. (2005). Turn-Taking Irregularities by African American Characters in the Movie "Why Do Fools Fall in Love". Journal, 7 (2), 104-115.

Wardhaugh, R. (1991). Introduction to Sociolinguistic. Oxford: Basil Blackwell. (1985). How Conversation Work. Oxford: Basil Blackwell.

Yule, G. (1996). The Study Of language. Cambridge: Cambridge University Press.

Zulchanzan, A. (2010). Irregular Turn-Takings in "Shakespeare In Love". Unpublished Thesis FKIP University of Halu Oleo.

Zimmerman, D.H. and C. West (1975). Sex Poles, interruption and sciences in conversation. In language and sex: Difference and Dominance. B. Thome and N. Henley (eds). Rowelry, M.A: Newbury House. 